\title{
PENINGKATAN KUALITAS HIDUP PASIEN PENYAKIT PARU OBSTRUKSI KRONIS MELALUI TEHNIK KONSERVASI ENERGI
}

\author{
${ }^{1}$ Nieniek Ritianingsih, ${ }^{2}$ Farial Nurhayati \\ ${ }_{1,2}$ Politeknik Kesehatan Kemenkes Bandung, Prodi Keperawatan Bogor
}

\begin{abstract}
Abstrak
Penelitian ini bertujuan untuk mengetahui pengaruh tehnik konservasi energi terhadap kualitas hidup pasien Penyakit Paru Obstruksi Kronis (PPOK). Teknik konservasi energi dapat diberikan pada pasien PPOK dengan tujuan dapat meningkatkan kualitas pernafasan, mengurangi kecemasan dan stress dan kualitas hidup dapat meningkat. Penelitian ini merupakan penelitian kuantitatif menggunakan metoda kuasi eksperimental dengan pendekatan pre test - post test control group design. Responden penelitian ini berjumlah 60 orang, untuk kelompok intervensi 30 orang untuk kelompok kontrol 30 orang responden. Hasil uji statistik didapatkan nilai $p$ value 0,014 maka dapat disimpulkan bahwa terdapat perbedaan yang signifikan antara kualitas hidup kelompok intervensi dengan kualitas hidup kelompok kontrol setelah dilakukan penerapan teknik konservasi energy. Dengan melaksanakan 6 prinsip dalam tehnik konservasi energi maka pasien dapat melaksanakan aktifitas dengan lebih terencana dan usaha minimal sehingga energi yang digunakan lebih efisien. Perawat agar menerapkan tehnik konservasi energi sebagai suatu program terstruktur dari intervensi keperawatan bagi pasien PPOK.
\end{abstract}

Kata kunci : Teknik konservasi energi, kualitas hidup, PPOK

\begin{abstract}
The aim of this study is to determine the effect of energy conservation techniques to the quality of life of patients with Chronic Obstructive Pulmonary Disease (COPD). Energy conservation techniques can be administered in COPD patients with the aim to improve the quality of breathing, reduce anxiety and stress and quality of life can be improved. This research is a quantitative research using quasi-experimental method approach to pre test - post test control group design. The respondents of this study of 60 people, for the intervention group of 30 people for the control group 30 respondents. Statistical test results obtained $p$ value of 0.014 , it can be concluded that there are significant differences between the quality of life of the intervention group with the control group after the implementation of energy conservation techniques. By carrying out six principles of energy conservation techniques, the patient can carry out activities with a more planned and minimal effort so that energy is used more efficiently. Nurses should implement energy conservation techniques as a structured program of nursing intervention for patients with COPD.
\end{abstract}

Keywords: Energy conservation techniques, quality of life, COPD

\section{PENDAHULUAN}

Penyakit Paru Obstruksi Kronik (PPOK) merupakan salah satu penyakit pernafasan dengan angka kesakitan dan kematian yang semakin meningkat (Kemenkes, 2008). Terdapat sekitar 210 juta penderita PPOK dan 3 juta orang diantaranya meninggal dunia (WHO, 2005).
Sementara di Indonesia sendiri PPOK menduduki peringkat ke 6 dari 10 penyebab tersering kematian (SKRT, 2008).

PPOK menyebabkan paru-paru kehilangan kemampuan untuk menyediakan oksigen ke tubuh. Pada PPOK akan terjadi fase ekspirasi lebih panjang diandingkan 
fase inspirasi dikarenakan terjadinya perubahan struktur pada bronkiolus terminal, terjadinya sumbatan jalan nafas, dan tertahannya udara dalam alveoli (Lemone \& Burke, 2011).

Gejala utama PPOK adalah sesak (dyspnea). Sesak ini sangat mempengaruhi berbagai aspek kehidupan pasien. hal ini akan berdampak pada keluarga, aktivitas sosial, aktivitas sehari hari dan akhirnya menyebabkan depresi dan kecemasan. Pasien dengan PPOK akan mengalami gangguan pertukaran gas, jalan nafas tidak efektif, perubahan pola nafas, intoleransi aktifitas, kekurangan nutrsi, dan perasaan takut. Dengan berbagai permasalahan tersebut kualitas hidup pasien PPOK akan menurun (Phips, Sands \& Marek, 2007).

Prinsip penanganan PPOK salah satunya adalah dengan teknik konservasi energi. Konservasi energi digunakan untuk meningkatkan kualitas hidup pasien PPOK. Teknik ini berguna untuk menghemat energi pada saat pasien melakukan aktivitas sehari hari, menurunkan dispnea dan meningkatkan kemampuan fungsional dan sosial pasien (Velloso \& Jardim, 2006). Saat melakukan aktivitas sehari hari pasien PPOK mengalami fatigue (kelelahan). Contohnya saat menyisir rambut saja pasien PPOK akan kesulitan, pola nafas menjadi cepat, irregular dan semakin dalam. Pernafasan yang tidak efektif ini menyebabkan tahanan terhadap pengembangan otot paru sehingga menyebabkan hiperventilasi. Pada orang normal mengangkat lengan membutuhkan konsumsi oksigen sebanyak $16 \%$ dan ventilasi paru sebanyak $24 \%$. data ini menggambarkan hanya dengan mengangkat tangan sangat mempengaruhi ventilasi dan penggunaan otot otot tubuh dan terjadi perubahan pada kapasitas dada dan abdomen sehingga kebutuhan ventilasi meningkat (Velloso \& Jardim, 2006).

Pasien dengan PPOK dalam melakukan tindakan yang sederhana seperti menyapu, menghapus papan tulis, mengganti bohlam lampu membutuhkan sekitar $50-60 \%$ kebutuhan oksigen dan terjadi peningkatan ventilasi sekitar $60-70 \%$. Sehingga pasien merasa tambah sesak dan ketidaknyamanan pada fisik (Velloso \& Jardim, 2006).

Dikarenakan $78 \%$ dari pasien PPOK mengalami dispnea dalam melakukan aktivitas sehari hari dan $50 \%$ diantaranya memerlukan bantuan. Hal ini membutuhkan suatu teknik untuk menghemat energy pada saat beraktivitas (Velloso \& Jardim, 2006).

Teknik konservasi energy merupakan salah satu teknik yang sangat dianjurkan pada pasien PPOK dengan tujuan untuk menurunkan dipsnea, termasuk mencegah dan mengurangi terjadinya disfungsi pemenuhan kebutuhan sehari-hari sehingga dapat meningkatkan kapasitas fungsi kualitas hidup pasien. Hasil riset sebelumnya ditemukan bahwa penggunaan teknik konservasi energy teuksi efesien dalam mengurangi sesak, konsumsi oksigen, produksi karbon dioksida dan frekuensi nadi dan peningkatan performa aktivitas sehari hari pada pasien PPOK (Velloso \& Jardim, 2006).

Kualitas hidup pasien PPOK berkurang sejalan dengan perkembangan penyakit. pasien dengan PPOK $50 \%$ nya mengalami keterbatasan dalam bekerja, $70 \%$ mengalami keterbatasan pergerakan fisik normal, $56 \%$ tidak dapat melakukan pekerjaan rumah tangga, 53\% keterbatasan social, $50 \%$ mengalami gangguan tidur dan $46 \%$ untuk kegiatan kekeluargaan (Schulman, Roncaa and Bucuvalas, 2000) Jacobs \& Angstadt (2007) menyatakan bahwa teknik konservasi energy dengan prinsip 4P (planning, pacing, prioritizing and potitioning) dapat meningkatkan kualitas hidup pasien dengan PPOK. Nici et. al (2005) juga menyatakan bahwa kualitas hidup pasien PPOK dapat ditingkatkan dengan konservasi energy.

Dunia keperawatan di Indonesia khususnya di Rumah sakit wilayah Bogor belum optimal penggunaan teknik konservasi energy belum optimal digunakan karena belum didukung oleh riset yang terkait. Perawat sebagai educator berperan penting dalam pemberian pendidikan 
kesehatan (therapy services) dengan memberikan teknik konservasi energy tersebut.

Berdasarkan fenomena di atas maka peneliti tertarik untuk melakukan penelitian tentang Pengaruh penerapan teknik konservasi energy terhadap kualitas hidup pasien Penyakit Paru Obstruksi Kronis (PPOK) di Bogor.

\section{METODE PENELITIAN}

Penelitian ini merupakan penelitian kuantitatif menggunakan metoda quasi eksperimental dengan pendekatan pre testpost test control group design. Desain ini digunakan untuk membandingkan hasil intervensi dua kelompok yaitu kelompok intervensi dimana dalam penelitian ini adalah pasien PPOK yang mendapatkan penerapan teknik konservasi energi dan kelompok kontrol yaitu pasien yang tidak mendapatkan teknik konservasi energy.

Penelitian ini dilakukan di ruang poliklinik paru RS M. Goenawan Patowidigdo Cisarua Bogor dengan waktu penelitian dilakukan pada bulan Januari s.d Desember 2016.

Sampel dalam penelitian ini adalah semua pasien PPOK yang menjalani rawat jalan di poliklinik RS Paru M. Goenawan Partowidigdo Cisarua Bogor. Adapun Tehnik pengambilan sampel yang digunakan adalah dengan cara purposive sampling, yaitu pengambilan sampel berdasar pertimbangan tertentu. Kriteria inklusi penelitian yang digunakan adalah

a. Bersedia menjadi responden dan kooperatif

b. Pasien sesak ringan

c. Pasien melaksanakan kontrol yang pertama pasca rawat inap

Besar sampel berdasarkan hasil perhitungan menggunakan uji hipotesis beda dua mean derajat kemaknaan $5 \%$, kekuatan uji $95 \%$, didapatkan besar sampel sebagai berikut :

$$
n=\frac{2 \sigma^{2}(z 1-\alpha+z 1-\beta)^{2}}{(\mu 1-\mu 2)^{2}}
$$

$$
\mathrm{n}=\frac{11 \cdot 2^{2}(1,96+1,64)^{2}}{(86,97-94,95)^{2}}
$$

$=25,5$ dibulatkan menjadi 26

Keterangan:

$\mathrm{n} \quad=$ Jumlah sampel minimal

$z 1-\alpha=$ Nilai $Z$ pada derajat kemaknaan 1.96 bila a $5 \%$

$z 1-\beta=$ Nilai $Z$ pada kekuatan 1,64 bila $\beta 5 \%$

$\sigma=$ Standar deviasi dari beda dua ratarata berpasangan terdahulu

$\mu \mathrm{o}=$ Rerata kualitas hidup sebelum exercise 86.97

$\mu \mathrm{a}=$ Rerata kualitas hidup setelah exercise 94.95

Ukuran sampel ditambah $10 \%$ dari sampel yang dihitung, menjadi 30 responden. Kelompok kontrol 30 responden, kelompok intervensi 30 responden.

Tehnik konservasi energy merupakan suatu latihan mengatur pernafasan ketika pasien beraktifitas sehari-hari dengan menerapkan prinsip $6 \mathrm{P}$ (prioritas aktifitas, perencanaan jadual kegiatan, mengukur keterbatasan diri, mengatur posisi, latihan pernafasan dan berperilaku positif. Pasien diajarkan tehnik tersebut menggunakan booklet.

Pertama-tama kelompok intervensi dan kelompok kontrol diukur nilai kualitas hidupnya, selanjutnya kelompok intervensi mendapatkan pengajaran tentang penerapan teknik konservasi energy selama $2 \times 60$ menit, sedangkan kelompok kontrol tetap mendapatkan asuhan keperawatan sesuai standar RS dan mendapatkan booklet teknik konservasi energi.

Lalu pasien diharapkan untuk menerapkan tehnik yang sudah diajarkan selama 1 bulan di rumah. Setelah 4 minggu maka dilakukan kembali pengukuran kedua untuk masing-masing kelompok. Hasil masing-masing kelompok kemudian dibandingkan Perhitungan AQ 20.

Uji statistik untuk seluruh analisis dilakukan dengan tingkat kemaknaan 95\% (alpha 0,05). Jenis analisis bivariat yang digunakan adalah dependent sample test (Paired t-test) dan independent t-test. Sebelum dianalisis dilakukan uji 
homogenitas pre intervensi pada kelompok kontrol dengan nilai 0,377 dan kelompok intervensi dengan nilai 1,14.

\section{HASIL PENELITIAN}

\section{Analisis Univariat}

Tabel 1. Distribusi frekuensi responden berdasarkan tingkat pendidikan

\begin{tabular}{lcc}
\hline $\begin{array}{c}\text { Variabel } \\
\text { Tingkat Pendidikan }\end{array}$ & F & (\%) \\
\hline \multicolumn{2}{c}{ KONTROL } \\
- Rendah & 22 & 73,4 \\
- Tinggi & 8 & 26,6 \\
\hline INTERVENSI & & \\
- Rendah & 30 & 100 \\
- Tinggi & 0 & 0 \\
\hline
\end{tabular}

Hasil analisis didapatkan dari 30 responden yang melaksanakan penerapan teknik konservasi energy pada kelompok intervensi seluruhnya adalah berpendidikan rendah sebanyak 30 orang (100\%). Sementara pada kelompok kontrol terbanyak adalah berpendidikan rendah sebanyak 22 orang (73.4\%) dan sebagian kecil yaitu sebanyak 8 orang (26,6\%) berpendidikan tinggi.

Tabel 2. Distribusi frekuensi responden berdasarkan jenis kelamin

\begin{tabular}{lcc}
\hline $\begin{array}{c}\text { Variabel } \\
\text { Jenis Kelamin }\end{array}$ & F & (\%) \\
\hline $\begin{array}{l}\text { KONTROL } \\
\text { - Laki-laki }\end{array}$ & 20 & 66,7 \\
- Perempuan & 10 & 33,3 \\
\hline INTERVENSI & & \\
- Laki-laki & 28 & 93,3 \\
- Perempuan & 2 & 6,7 \\
\hline
\end{tabular}

Hasil analisis didapatkan dari 30 responden yang melaksanakan penerapan teknik konservasi energy pada kelompok intervensi sebagian besar berjenis kelamin laki-laki yaitu 28 orang $(93,3 \%)$ dan sebagian kecil yaitu 2 orang $(6,7 \%)$ bahwa berjenis kelamin perempuan. Sementara pada kelompok kontrol sebagian besar responden berjenis kelamin laki-laki yaitu 20 orang $(66,7 \%)$ dan perempuan yaitu 10 orang (33.3\%).

Tabel 3. Distribusi frekuensi responden berdasarkan pekerjaan

\begin{tabular}{lll}
\hline \multicolumn{1}{c}{$\begin{array}{c}\text { Variabel } \\
\text { Pekerjaan }\end{array}$} & F & (\%) \\
\hline $\begin{array}{l}\text { KONTROL } \\
\text { - Bekerja } \\
\text { - Tidak Bekerja }\end{array}$ & 14 & 46,7 \\
\hline $\begin{array}{l}\text { INTERVENSI } \\
\text { - Bekerja }\end{array}$ & 18 & 53,3 \\
- Tidak Bekerja & 12 & 40 \\
\hline
\end{tabular}

Hasil analisis didapatkan dari 30 responden yang melaksanakan penerapan teknik konservasi energy pada kelompok intervensi lebih dari setengah yaitu 18 orang $(60 \%)$ bekerja dan kurang dari setengahnya yaitu 12 orang (40\%) tidak bekerja. Sementara pada kelompok kontrol sebagian besar responden tidak bekerja yaitu 16 orang $(53,3 \%)$ dan kurang dari setengahnya responden bekerja yaitu 14 orang $(46,7 \%)$.

Tabel 4. Distribusi frekuensi responden berdasarkan Usia responden

\begin{tabular}{|c|c|c|c|c|}
\hline Variabel & Mean & SD & $\begin{array}{l}\text { Min- } \\
\text { Maks }\end{array}$ & $\begin{array}{c}95 \% \\
\mathrm{Cl}\end{array}$ \\
\hline Umur & $\begin{array}{l}\text { Kontrol } \\
62,87\end{array}$ & 6,38 & $55-74$ & $\begin{array}{l}60,49- \\
65,25\end{array}$ \\
\hline & $\begin{array}{l}\text { Intervensi } \\
64,97\end{array}$ & 6,18 & $54-75$ & $\begin{array}{l}62,66- \\
67,28\end{array}$ \\
\hline
\end{tabular}

Untuk kelompok intervensi hasil analisis didapatkan rerata umur responden kelompok intervensi adalah 64,97 tahun (95\% Cl: 62,66-67,28), dengan standar deviasi 64,97 tahun. Umur termuda 54 tahun dan umur tertua 75 tahun. Sedangkan Hasil analisis didapatkan rerata umur responden kelompok kontrol adalah 62,87 tahun (95\%Cl: $60,49-65,25)$, dengan standar 
deviasi 6,38 tahun. Umur termuda 55 tahun dan umur tertua 74 tahun.

Tabel 5. Rerata kualitas hidup pre dan post pada kelompok Kontrol

\begin{tabular}{lcccc}
\hline Variabel & Mean & SD & $\begin{array}{c}\text { Min - } \\
\text { Mak }\end{array}$ & 95\%Cl \\
\hline Kualitas & 38,50 & 9,46 & $23-55$ & $34,97-$ \\
hidup pre & & & & 42,03 \\
\hline Kualitas & 38,67 & 16,81 & $13-63$ & $32,39-$ \\
hidup post & & & & 44,94 \\
\hline
\end{tabular}

Hasil analisis didapatkan rerata kualitas hidup pre pada kelompok kontrol adalah $38,50 \% \quad(95 \% \mathrm{Cl}: \quad 34,97-42,03)$, dengan standar deviasi $9,46 \%$. Kualitas hidup terendah $23 \%$ dan kualitas hidup tertinggi 55\%. Hasil estimasi interval 95\% diyakini bahwa rerata kualitas hidup pre pada kelompok kontrol adalah antara 34,97$42,03 \%$. Rerata kualitas hidup post pada kelompok kontrol adalah 38,67\% (95\% Cl: 32,39-44,94), dengan standar deviasi $16,81 \%$. Kualitas hidup terendah $13 \%$ dan kualitas hidup tertinggi $63 \%$. Hasil estimasi interval 95\% diyakini bahwa rerata kualitas hidup post pada kelompok kontrol adalah antara $32,39-44,94 \%$.

Tabel 6. Rerata kualitas hidup pre dan post pada kelompok Intervensi

\begin{tabular}{lcccc}
\hline \multicolumn{1}{c}{ Variabel } & Mean & SD & $\begin{array}{c}\text { Min - } \\
\text { Mak }\end{array}$ & 95\% Cl \\
\hline $\begin{array}{l}\text { Kualitas } \\
\text { hidup pre }\end{array}$ & 35,50 & 20,45 & $10-75$ & $27,86-$ \\
& & & & 43,14 \\
\hline $\begin{array}{l}\text { Kualitas } \\
\text { hidup post }\end{array}$ & 50,33 & 18,75 & $28-90$ & $43,33-$ \\
& & & & 57,34 \\
\hline
\end{tabular}

Hasil analisis didapatkan rerata kualitas hidup pre pada kelompok intervensi adalah $\quad 35,50 \% \quad(95 \% \mathrm{Cl}: \quad 27,86-43,14)$, dengan standar deviasi $20,45 \%$. Kualitas hidup terendah $10 \%$ dan kualitas hidup tertinggi $75 \%$. Hasil estimasi interval $95 \%$ diyakini bahwa rerata kualitas hidup pre pada kelompok intervensi adalah antara $27,86-43,14 \%$. Rerata kualitas hidup post pada kelompok intervensi adalah 50,33\% (95\% Cl: 43,33-57,34), dengan standar deviasi $18,75 \%$. Kualitas hidup terendah $28 \%$ dan kualitas hidup tertinggi $90 \%$. Hasil estimasi interval 95\% diyakini bahwa rerata kualitas hidup post pada kelompok intervensi adalah antara 43,33-57,34\%.

\section{Analisis Bivariat}

Tabel 7. Perbedaan rerata kualitas hidup pre dan post pada kelompok kontrol

\begin{tabular}{lcccc}
\hline Variabel & Mean & SD & SE & P value \\
\hline $\begin{array}{lcccc}\text { Kualitas } \\
\text { hidup pre }\end{array}$ & 38,5 & 9,46 & 1,73 & 0,955 \\
\cline { 1 - 3 } & 38,67 & 16,81 & 3,01 & \\
$\begin{array}{l}\text { Kualidup post } \\
\text { hidun }\end{array}$ & & & & \\
\hline
\end{tabular}

Rerata kualitas hidup pasien pre intervensi pada kelompok kontrol adalah $38,50 \%$, dengan standar deviasi $9,46 \%$. Pada pengukuran kedua kualitas hidup kelompok kontrol didapat rerata kualitas hidup pasien adalah $38,67 \%$ dengan standar deviasi $16,81 \%$. Nilai mean perbedaan antara pengukuran pertama dan kedua kualitas hidup adalah 0,17 dengan standar deviasi 16,04. Hasil uji statistik didapatkan nilai 0,955 maka dapat disimpulkan tidak ada perbedaan kualitas hidup pre dan kualitas hidup post pada kelompok kontrol.

Tabel 8. Perbedaan rerata kualitas hidup pre dan post pada kelompok Intervensi di RSPG Cisarua, tahun 2016

\begin{tabular}{lcccc}
\hline \multicolumn{1}{c}{ Variabel } & Mean & SD & SE & P value \\
\cline { 1 - 4 } $\begin{array}{l}\text { Kualitas } \\
\text { hidup pre }\end{array}$ & 35,50 & 20,45 & 3,73 & 0,001 \\
\cline { 1 - 3 } & 50,33 & 18,75 & 3,42 & \\
$\begin{array}{l}\text { Kudup post } \\
\text { hidup }\end{array}$ & & & & \\
\hline
\end{tabular}

Rerata kualitas hidup pasien pre intervensi pada kelompok intervensi adalah $35,50 \%$, dengan standar deviasi $20,45 \%$. Pada pengukuran kedua kualitas hidup 
setelah dilakukan penerapan teknik konservasi energy didapat rerata kualitas hidup pasien adalah $50,33 \%$ dengan standar deviasi $18,75 \%$. Nilai mean perbedaan antara pengukuran pertama dan kedua kualitas hidup adalah 14,83 dengan standar deviasi 15,91. Hasil uji statistic didapatkan nilai 0,000 maka dapat disimpulkan ada perbedaan yang signifikan antara kualitas hidup pre dan kualitas hidup post pada kelompok intervensi.

Tabel 9. Perbedaan rerata kualitas hidup pre menurut intervensi penerapan teknik konservasi energy pada pasien PPOK di RSPG Cisarua, tahun 2016

\begin{tabular}{ccccc}
\hline $\begin{array}{c}\text { Teknik } \\
\text { konservasi } \\
\text { energy }\end{array}$ & Mean & SD & SE & P value \\
\cline { 1 - 3 } Kontrol & 38,50 & 9,46 & 1,73 & 0,47 \\
\cline { 1 - 3 } Intervensi & 35,50 & 20,4 & 3,73 & \\
\hline
\end{tabular}

Rerata kualitas hidup pasien pre intervensi pada kelompok kontrol adalah $38,50 \%$, dengan standar deviasi $9,46 \%$. Pada pengukuran pertama kualitas hidup sebelum dilakukan penerapan teknik konservasi energy pada kelompok intervensi didapat rerata kualitas hidup pasien adalah $35,50 \%$ dengan standar deviasi $20,45 \%$. Hasil uji statistik didapatkan nilai $p$-value 0,47 maka dapat disimpulkan tidak ada perbedaan yang signifikan antara kualitas hidup kelompok kontrol dengan kualitas hidup kelompok intervensi sebelum dilakukan penerapan teknik konservasi energy.

Tabel 10. Perbedaan rerata kualitas hidup post menurut intervensi penerapan teknik konservasi energy pada pasien PPOK di RSPG Cisarua, tahun 2016

\begin{tabular}{ccccc}
\hline $\begin{array}{c}\text { Teknik } \\
\text { konservasi } \\
\text { energy }\end{array}$ & Mean & SD & SE & P value \\
\cline { 1 - 4 } Kontrol & 38,67 & 16,8 & 3,07 & 0,014 \\
\cline { 1 - 3 } Intervensi & 50,33 & 18,7 & 3,42 &
\end{tabular}

Rerata kualitas hidup pasien post intervensi pada kelompok kontrol adalah $38,67 \%$, dengan standar deviasi $16,81 \%$. Pada pengukuran kedua kualitas hidup setelah dilakukan penerapan teknik konservasi energy pada kelompok intervensi didapat rerata kualitas hidup pasien adalah $50,33 \%$ dengan standar deviasi $18,75 \%$. Hasil uji statistik didapatkan nilai $p$ value 0,014 maka dapat disimpulkan ada perbedaan yang signifikan antara kualitas hidup kelompok kontrol dengan kualitas hidup kelompok intervensi setelah dilakukan penerapan teknik konservasi energy.

\section{PEMBAHASAN}

Pada PPOK terjadi obstruksi bronkiolus sehingga meningkatkan tahanan saluran nafas dan meningkatkan kerja penafasan. Inspirasi merupakan gerakan aktif dengan menggunakan otot-otot pernafasan, maka udara masih bisa masuk melalui sumbatan dan masuk melalui alveolus. Tetapi karena proses ekspirasi merupakan proses yang pasif yang hanya berdasarkan elastisitas paru, maka tidak semua udara hasil inspirasi dapat dikeluarkan lagi dan akan menyebabkan adanya udara sisa dalam alveoli. Alveoli menjadi teregang dan terjadi distensi alveolus (air trapping) dan pasien menjadi sesak (Black \& Hawk, 2009).

Sesak yang ditimbulkan penyakit PPOK akan mengakibatkan keterbatasan fungsi pasien, baik fungsi social maupun aktifitas sehari-harinya sehingga akan mengurangi kualitas hidupnya.

Menurut Menurut Black \& Hawk, (2009) salah satu penatalaksanaan sesak pada pasien PPOK adalah tehnik konservasi energy. Tehnik konservasi energy adalah suatu teknik mengatur pernafasan ketika pasien beraktivitas sehari-hari sehingga terjadi penghematan energy dan mencegah fatigue dan sesak.

Dengan 6 prinsip yang dilakukan yaitu Prioritize your activities (Prioritas aktivitas), Plan your schedule (Perencanaan jadual), Pace yourself (Keterbatasan diri), 
Positioning (Posisi), Pursed lips breathing (Latihan pernafasan mulut), dan Positive attitude (perilaku positif) maka pasien dapat dibantu kembali memenuhi tugas fungsinya dengan lebih efisien sehingga pasien akan merassa lebih berpartisipasi pada aktifitas dengan lebih berarti (Jacobs \& Karie, 2007).

Menurut Barnett (2008) melalui tehnik konservasi energy maka pasien akan diajarkan cara menghemat energy dalam pelaksanaan tugas tanpa menimbulkan kelelahan dan sesak. Melalui tehnik konservasi energy pasien akan diajarkan menempatkan kegiatan dengan terencana tanpa terburu-buru dengan disertai fase istirahat. Hasil riset dari singh (2003) tehnik konservasi energy yang merupakan bagian dari program rehabilitasi paru secara signifikan berpengaruh terhadap peningkatan kualitas hidup pasein PPOK.

Penerapan tehnik konservasi energy merupakan bagian dari program rehabilitasi paru. Dengan pembagian menjadi 4 area yaitu: planning, pacing, prioritising and positioning diharapkan pasien dapat mengerjakan sesuatu dengan usaha minimal sehingga dapat mengurangi sesak saat memenuhi kebutuhan sehari-hari (Jacobs \& Angstadt, 2007).

Strategi konservasi energy merupakan salah satu "best practise in nursing" guna mengurangi sesak/dyspnea pada pasien PPOK (Bailey, 2013). Melalui pendidikan kesehatan yang diajarkan maka pasien akan diajarkan untuk melaksanakan aktifitasnya secara terencana dan tehnik yang benar sehingga energy pasien dapat termaksimalkan.

\section{KESIMPULAN}

Terdapat perbedaan yang signifikan antara kualitas hidup pasien PPOK pada kelompok intervensi dan kelompok kontrol sesudah penerapan tehnik konservasi energi.

\section{SARAN}

Bagi rumah sakit agar menjadikan penerapan tehnik konservasi energi sebagai suatu program terstruktur dari intervensi keperawatan bagi pasien PPOK, bagi pasien agar turut bersama-sama berpartipasi aktif dan menjadikan penerapan tehnik konservasi energy menjadi suatu kegiatan mandiri yang dapat dilakukan di rumah, dan bagi peneliti selanjutnya dapat diteliti secara kualitatif tentang penerapan tehnik konservasi energi dalam meningkatkan kualitas hidup pasien PPOK.

\section{DAFTAR PUSTAKA}

Barnett M., (2009). Non-pharmacological management of COPD Journal of Community Nursing; Apr 2008; 22, 4; Public Health Database pg. 30-33.

Black, J.M., \& Hawk, J.H. (2009). Medical surgical nursing: Clinical management for positive outcome. $8^{\text {th }}$ edition. Missouri: Elsevier Saunders

COPD Foundation, (2015) Breathing Techniques.

http://www.copdfoundation.org/What-isCOPD/Living-with-COPD/BreathingTechniques.aspx

Holland, A.E., Hill, C.J., Jones, A.Y., Mc Donald, C.F., (2012). Breathing exercises for chronic obstructive pulmonary disease (Review). The Cochrane Collaboration. Published by John Wiley \& Sons, Ltd. http://www.update-software.com /bcp/wileypdf/en/cd008250.pdf

Jacobs, Mimi, and Angstadt, Karie, (2007), 4 $P s$ to Improve Quality of Life in Residents with COPD, Assisted Living Consult March/April 2007 pg 27-30. http://www.assistedlivingconsult.com/is sues/03-02/ALC03-02_COPD.pdf

Manal S., Asmaa H., Hanan S., (2013) Improving breathlessness and fatigue in patient with COPD. J Am Sci 2013;9(12):470-482.

http://www.jofamericanscience.org. 64

Monahan. D. Frances \& Neighbors Marianne (2008). Medical-Surgical Nursing Foundation for Clinical Practice. Philadelphia: WB Saunder company

Nici.L, Donner. C, Wouters.E, Zuwallack.R, Ambrosino.N, Bourbeau.J, Carone. M, 
Celli. B, et al (2005). Society statetment on Pulmonary Rehabilitation. American thoracic society documents.

Phipps, J.W., Sand,K.J., Marek,F.J., (2007). Medical-surgicalNursing-Heath and illness perpectives. 8 th edition. St.Louis, Missouri: Mosby,Inc.

Pulmonary Rehabilitation Educational Booklet Energy Conservation Techniques Hospital Authority Coordinating Committee in Occupational Therapy, Hospital Authority. (http://www21.ha.org.hk)

Schulman, Ronca and Bucuvalas. Inc (2000). Confronting COPD in America. Funded by Glaxo Smith Kline.

Singh V., (2003). Oulmobary rehabilitation in patient COPD. Indian J.Chest. Dis Allied SCi 2003,45:13-17

SKRT 2008, Profil Kesehatan Indonesia 2008, Jakarta, Departemen Kesehatan RI. http://www.depkes.go.id

St George Respiratory Quetioner ( Bahasa Indonesia).

http://repository.maranatha.edu

Diakses tanggal 25 Agustus 2015.

Velloso,M. Jardim R. J. (2006). Functionality of patients with COPD: energy conservation technique. Journal Bras Pneumol. 2006: 32(6):580-6.

Velloso,M. Jardim R. J. (2006). Study of energy expenditure during the activities of daily living using body position recommended by energy conservation technique in COPD patients. Chess.2006:130(1):126-32.

WHO, (2009). The World Health Organization Quality of Life http://www.who.int Diakses tanggal 25 Agustus 2015.

Yuarsa, T.A., Yunus, F., \& Antariksa, B. (2013). Korelasi Peningkatan Kualitas Hidup dan Prognosis Penderita Penyakit paru obstruktif Kronik dengan CAT, SGRQ dan BODE di Rumah Sakit Persahabatan Jakarta. J. Respir Indo Vol 33 No. 1. Januari 2013. http://jurnalrespirologi.org/wpcontent/uploads/2013/03/jri-33-1-8.pdf diakses pada tanggal 25 Agustus 2015 www.livingwellwithcopd.com Managing your breathing and saving your energy. 